\title{
Assessment of Antibiotic Use in a Secondary Care Referral Hospital of South India
}

\author{
B. Dhanalakshmi ${ }^{1}$, Dr. Mohanraj Rathinavelu ${ }^{2}$,Dr. Y. Padmanabha Reddy ${ }^{3}$ \\ ${ }^{I}$ (Pharm.D Intern, Department of Pharmacy Practice, Raghavendra Institute of Pharmaceutical Education and \\ Research, India). \\ ${ }^{2}$ (Assistant Professor, Department of Pharmacy Practice, Raghavendra Institute of Pharmaceutical Education \\ and Research, India). \\ ${ }^{3}$ Professor and Principal, Department of Analysis, Raghavendra Institute of Pharmaceutical Education and \\ Research, India).
}

\begin{abstract}
The emergence of antibiotic resistant bacteria is major problem throughout the world and rational use of antibiotics is therefore very important. Good infection control practice is a critical component for success of such programme. This six months prospective observational study was designed to evaluate the appropriateness of antibiotic use in a secondary care referral hospital of South India. The data of all in patients $(n=100)$ were collected by obtaining a proper consent. Maximum of $52.78 \%$ patients had culture sensitivity test being done, which may taken as a indication for being rational. The results revealed that the purpose of antibiotics prescribed was for prophylaxis (15\%), empirically (37\%) and therapeutically $48 \%$.In the study population ( $n=49)$, totally 110 antibiotics were prescribed, $71.88 \%$ on dual therapy and $28.12 \%$ were on three antibiotics and the mean number of antibiotics prescribed was 2.28. In the overall population, $61.65 \%$ were administrated intravenously and 39.35\% of oral antibiotics The major organisms identified were E.coli (28.90\%) and Amikacin had shown the highest sensitivity in E.coli (86.4\%). Totally 31 drugs of antibacterials were listed in National List of Essential Medicine. Out of 31, 15 antibacterials were prescribed in study population.
\end{abstract}

Keywords: Antibacterials, Antibiotics, Observational study, Prescribing pattern, Rational drug use.

\section{Introduction}

Antibacterial medications are considered as the greatest discovery of the twentieth century. The word "antibiotics" comes from the Greek word anti ("against") and bios ("life").The first antimicrobial was discovered in the mid-20 and many new molecules were discovered between 1960 and 1980. This 'golden era of antibiotics' saw a dramatic fall in the mortality from infections. Since the 80's, not many new class of molecules have been discovered and the funding into antimicrobial research is on the decline and now deaths due to resistant infections is slowly increasing; mortality due to nosocomial infections is now 4 times that due to road traffic accidents[1].Rational drug use (RDU) is conventionally defined as the use of an appropriate, efficacious, safe and cost-effective drug given for the right indication in right dose and formulation, at right intervals and for the right duration of time. The promotion of rational drug use involves a wide range of activities such as the adoption of essential drug concept, training of health professionals in rational drug use and the development of evidence-based clinical guidelines. Unbiased and independent drug information, continuing education of health professionals, consumer education and regulatory strategies are also vital to promote rational drug use.

The importance of RDU relates to its impact on the health of individuals and communities, health care costs and the environment. Irrational drug use leads to ineffective and unsafe drug treatment, worsening or prolonging of illness, and adverse drug reaction. Wide spread antibiotic resistance is partly due to the irrational use of antibiotics.

WHO defines rational use of drug as "Rational use of drugs requires that patients receive medications appropriate to their clinical needs, in doses that meet their own individual requirements for an adequate period of time, and the lowest cost to them and their community."[2].

Antibacterials are the most important weapons in our hands. There are more than 100 antibacterials available today, and each one has its own spectrum of activity, adverse effect profile and cost. The doctor should consider many factors before prescribing an antibacterial agent so as to make the treatment most effective with least adverse effects and cost. The following factors should be considered while prescribing an antibacterial agent, like site of infection, type of infection, severity of infection, isolate and its sensitivity, source of infection, host factors and drug related factors. It has been observed that the three commonest reasons for prescribing antibacterials are fever, sore throat and diarrhea.

Assessment of the rational use of antibiotics [3]: To evaluate the quality of prescribing of antimicrobial drugs by audits, the criteria developed by kunin et al., have traditionally been used. In the past, the classification was 
mainly based on the authority of infectious diseases specialists who performed the evaluation. Usage was categorized as appropriate, probably appropriate, inappropriate due to less costly alternatives, dose adaptation needed, or totally inappropriate. Because the formulation of the criteria was rather specific, these original criteria have been modified by several authors. They have adapted or extended these criteria in order to be able to judge specific parameters. The following are some of the quality evaluation of criteria for antimicrobial therapy which can be used to assess the rationality of antibiotic use. They are: (a) Is there enough information to allow for categorization (b) Is the clinical picture compatible with an infection(c) Is there an indication for treatment with antibiotics (d) Is the choice of anti-microbial drug adequate (e) Is the duration of treatment appropriate (f) Is the dosage is correct ( $\mathrm{g}$ ) Is the timing appropriate.

Hence, the current study entitled "Evaluation of Antibiotic use in a Secondary care referral Hospital" was aimed to achieve the following objectives

* To analyse the prescribing pattern of antibiotics.

* To evaluate the appropriateness of antibiotics used.

* To identify the most prevalence organism and its sensitivity and resistance pattern.

\section{Methodology}

The proposed study entitled "Evaluation of Antibiotic use in a Secondary Care Referral Hospital" was planned and carried out as given below.

2.1 Study site: All the wards of General Medicine, Care \& Supportive Centre and General Surgery departments of a 300 bedded secondary care referral hospital.

2.2 Study design: Prospective - Observational Study.

2.3 Study period: 06 months.

2.4 Plan of study

2.4.1 Phase I:

Submission of protocol and obtaining consent from hospital authority.

Literature survey: The literatures supporting the study were gathered from various sources such as:

British Medical Journal, American Medical Journal, Journal of Clinical Pharmacy and Therapeutics, Journal of Pharmacy Practice, The Annals of pharmacotherapy, Journals of antimicrobial chemotherapy, Journal of national medical association, Indian journal on medical microbiology

\section{Designing of: Data entry format, Patient information \& consent form.}

Data entry form for incorporating inpatient details were designed and the format contains provision to enter the details such as name, age, sex, height, weight, IP. No, date of admission, date of discharge, vital signs, reason for admission, past medical history, past medication history, and any predisposing factors. Provision was given in the format for entry of details like Blood sugar levels, Blood counts, Liver function test, Renal function test, Electrolytes, Urine examination, Lipid profile, Diagnosis, Drug chart, ADR monitoring chart and Drug interaction chart and dose and any interventions.

Patient information form has been prepared, to inform the patients or the care givers about the purpose and the necessity of the study by providing the patient information form and assured them that the confidentiality will be strictly maintained and also it will help the betterment of patients' health.

Patient Consent form has also been prepared and written consent was collected from all the patients or from the caregivers by using patient consent form after providing the information format.

Inclusion Criteria

* All patients of either sex who were getting admitted to the study site during study period and were prescribed with at least one antibiotic and in whom the culture sensitivity test is performed.

\section{Exclusion Criteria}

* The patients who all are unwilling to participate in the study and terminally ill, will be not included in the study.

\subsubsection{Phase II:}

Data collection through standard data entry format.

Literature survey.

Data analysis.

* Evaluate the appropriateness of antibiotics use.

* Analyse the prescribing pattern of antibiotics.

* Application of statistical tools.

\subsubsection{Phase III:}

Literature survey.

Data analysis: The obtained data will be thoroughly analyzed to evaluate the appropriateness of antibiotic use and utilization pattern of antibiotics and drug interactions will also be noted. Statistical analysis was performed using the SPSS11.0. ANOVA tests were used to study differences between groups of variables of age, number 
of drugs prescribed, number of antibiotics prescribed and length of stay. ANOVA test was performed using number of subjects, mean and standard deviation. $P$ value less than 0.05 was considered statistically significant. Association between the age, number of drugs and length of stay were done by Pearson's correlation coefficient.

Preparation and submission of reports.

\section{Results and Discussions}

In the study period, the study site had 100 patients as per inclusion and exclusion criteria. 49 patients had shown a positive culture study reports for urine, sputum, pus and blood samples. Distribution of patients in various departments and their status on cultural sensitivity were thoroughly analyzed and reported in Table. 1.

Table. 1. Distribution of patients in various departments and their status on cultural sensitivity

\begin{tabular}{|c|c|c|c|c|}
\hline S.No. & Departments & Overall $(\mathrm{n}=100)$ & Study(n=49) & \% Culture Sensitivity \\
\hline 1 & General medicine & 44 & 22 & $50 \%$ \\
\hline 2 & Care \& Supportive centre & 27 & 13 & $48.15 \%$ \\
\hline 3 & Surgical & 29 & 14 & $48.28 \%$ \\
\hline
\end{tabular}

The results on Gender categorization had revealed that both the overall and study population had a predominantly male patients. The same was given in the Figure. 1

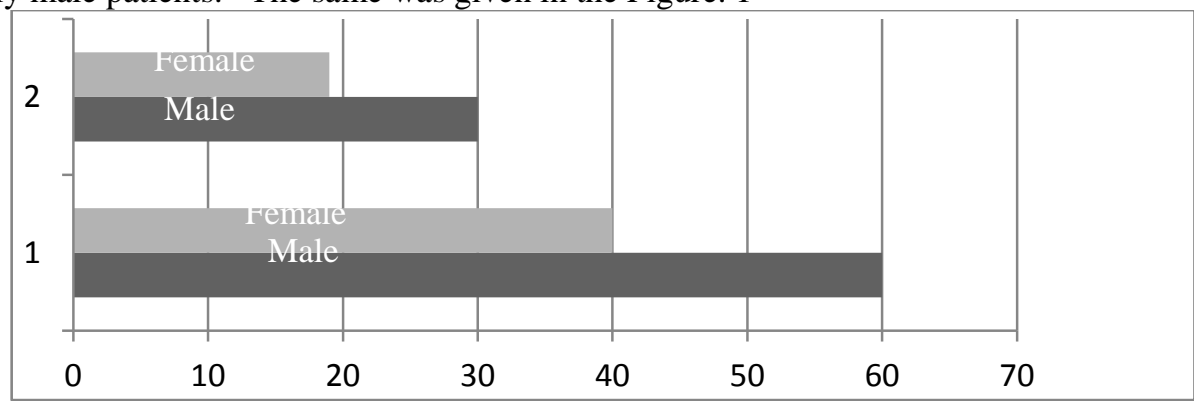

Fig.1 Gender Categorization

The overall population and the study population were categorized based on their age and results were given in Table. 2. From the results it was understood that in both overall and study population patients in Late adulthood (51-65) were found to be more.

Table. 2. Age Categorization

\begin{tabular}{|c|c|c|c|}
\hline S. No. & $\begin{array}{c}\text { Age group } \\
\text { (range in yrs) }\end{array}$ & $\begin{array}{c}\text { Overall } \\
(\mathrm{n}=100)\end{array}$ & $\begin{array}{c}\text { Study } \\
(\mathrm{n}=49)\end{array}$ \\
\hline 1 & $\begin{array}{c}\text { Early adulthood } \\
(19-35)\end{array}$ & 08 & 04 \\
\hline 2 & $\begin{array}{c}\text { Adulthood } \\
(36-50)\end{array}$ & 22 & 20 \\
\hline 3 & $\begin{array}{c}\text { Late adulthood } \\
(51-65)\end{array}$ & 41 & 11 \\
\hline 4 & $\begin{array}{c}\text { Young old } \\
(66-74) \\
\text { Old } \\
(75-84)\end{array}$ & 23 & 03 \\
\hline 5 & & 06 & 03 \\
\hline
\end{tabular}

Smokers were seen to have an increased risk of contracting infections, especially those of the respiratory system, leading to an increased use of antibiotics results of which been tabulated in Table. 3 .

Table. 3. Social History

\begin{tabular}{|c|c|c|c|}
\hline S. No. & Social History & Overall $(\mathrm{n}=100)$ & Study $(\mathrm{n}=49)$ \\
\hline 1 & Smoker & 18 & 09 \\
\hline 2 & Alcoholic & 15 & 07 \\
\hline 3 & Tobacco & 06 & 03 \\
\hline 4 & None of the above & 61 & 30 \\
\hline
\end{tabular}


In the overall population, the most common condition diagnosed was found to be $44 \%$ of all Respiratory Tract Infections and $19 \%$ of UTI. The study population had $4.41 \%$ UTI, 3.92\% LRTI, $1.96 \%$ asthma. The details of other diagnosis were given in the Table. 4. A similar result was obtained by Rashid et al (2011) who had reported that the major indications for antibiotics were diseases of the respiratory system (28\%).

Table. 4. Diagnosis

\begin{tabular}{|c|c|c|c|}
\hline S. No. & Type of Diseases & Overall $(\mathrm{n}=100)$ & Study $(\mathrm{n}=49)$ \\
\hline 1 & LRTI & 16 & 08 \\
\hline 2 & COPD & 04 & 02 \\
\hline 3 & Asthma & 08 & 04 \\
\hline 4 & TB & 12 & 06 \\
\hline 5 & Acute bronchitis & 04 & 02 \\
\hline 6 & Pneumonia & 10 & 05 \\
\hline 7 & Viral pyrexia & 09 & 05 \\
\hline 8 & Dengue fever & 19 & 04 \\
\hline 9 & UTI & 03 & 09 \\
\hline 10 & Meningitis & 07 & 01 \\
\hline 11 & Sinusitis & & 03 \\
\hline
\end{tabular}

The co morbid conditions prevailing in both overall populations \& study were having diabetes mellitus, hypertension. The details of other Co- morbid conditions were given in the Table. 5. The high incidence of diabetes as a co morbidity contributed to the higher chance of infections and hence increased antibiotic use.

Table. 5. Co - morbid Conditions

\begin{tabular}{|c|c|c|}
\hline S.No. & Co morbid conditions & $\mathrm{n}=49$ \\
\hline 1 & Diabetes & 31 \\
\hline 2 & Hypertension & 11 \\
\hline 3 & BPH & 02 \\
\hline 4 & CHF & 02 \\
\hline 5 & Liver cirrhosis & 01 \\
\hline 6 & Hepatomegaly & 01 \\
\hline 7 & Peptic ulcer & 01 \\
\hline
\end{tabular}

Totally 553 different of drugs were prescribed to the overall population; the details of other drugs prescribed were given in the Table. 6 .

Table. 6. Drugs Prescribed

\begin{tabular}{|c|c|c|c|}
\hline S. No. & Drugs & 0verall $(\mathrm{n}=553)$ & Study $(\mathrm{n}=270)$ \\
\hline 1 & Anti-ulcer & $90(16.27)$ & $44(16.29)$ \\
\hline 2 & Multivitamins & $92(16.63)$ & $45(16.68)$ \\
\hline 3 & Analgesics & $84(15.19)$ & $41(15.18)$ \\
\hline 4 & Anti-asthmatics & $63(11.39)$ & $27(10.0)$ \\
\hline 5 & Anti-diabetics & $55(9.95)$ & $14(5.18)$ \\
\hline 6 & NSAIDS & $28(5.06)$ & $17(6.29)$ \\
\hline 7 & Laxatives & $34(6.15)$ & $13(4.81)$ \\
\hline 8 & Anti-tubercular & $30(5.42)$ & $11(4.07)$ \\
\hline 10 & Antihypertensive & $22(3.98)$ & $07(2.6)$ \\
\hline 11 & Diuretics & $14(2.53)$ & $05(1.85)$ \\
\hline 12 & Anti-emetics & $11(1.99)$ & $03(1.11)$ \\
\hline 15 & Antihistamine & $06(1.08)$ & $06(2.22)$ \\
\hline 20 & Anti-amoebics & $12(2.16)$ & $02(0.74)$ \\
\hline 21 & Antispasmodics & $04(0.7)$ & $04(1.48)$ \\
\hline 22 & Alkalisers & $08(1.44)$ & \\
\hline
\end{tabular}

Totally 225 antibiotics were prescribed for the overall population and the mean was $2.28 \pm 1.08$ with the maximum of 4 antibiotics and the minimum of 1 antibiotic. In study population, 110 antibiotics were prescribed. The mean was $2.32 \pm 0.56$ with the maximum of 2 antibiotics and the minimum 1 antibiotic. The same was shown in the Table. 7 . 
Table. 7. Drugs Prescribed

\begin{tabular}{|c|c|c|c|}
\hline S. No. & Number of Antibiotics Prescribed & Overall(n=225) & Study(n=110) \\
\hline 1 & 1 & 05 & 02 \\
\hline 2 & 2 & 28 & 14 \\
\hline 3 & 3 & 08 & 04 \\
\hline 6 & 6 & 01 & - \\
\hline
\end{tabular}

Totally 225 antibiotics were prescribed for the overall population, $61.65 \%$ were administrated intravenously and $39.35 \%$ of oral antibiotics.

Route of administration:

The study population had, $73.63 \%$ of intravenously administrated and $26.27 \%$ orally. A study by Briquet et al (2008) evaluated the impact of converting IV administration of antibiotics over oral administration. The reported advantages were less preparation time, easier administration, lower risk of complications and lesser cost.

\section{Organisms Isolated:}

The study population $(\mathrm{n}=49)$. Six different organisms were isolated. The major organisms identified were E.coli 28.9\% (37), staphylococcus aureus 21.87\% (28), Staphylococcus pneumonia 21.09\% (27), Klebsiella pneumonia 15.62\% (20), Pseudomonas 8.59\% (11), and Streptococcus species 3.9\% (05). A similar study by Mettler et al in 2007 found that Escherichia coli was the most frequent organism encountered followed by Staphylococcus aureus, Streptococcus pneumoniae and Klebsiella pneumoniae.

The organisms isolated were obtained from different specimen. Table. 8. reveals the different specimens from which they were isolated.

Table. 8. Organisms Isolated

\begin{tabular}{|c|c|c|c|}
\hline S.No & Specimen & $\mathrm{n}=49$ & Overall \\
\hline 01 & Blood & 06 & 12 \\
\hline 02 & Pus & 08 & 16 \\
\hline 03 & Urine & 21 & 43 \\
\hline 04 & Sputum & 14 & 29 \\
\hline
\end{tabular}

Specimens Vs Organism: E.coli was highly prevalent in urine sample; Staphylococcus pneumonia was most common in sputum. Klebsiella pneumonia was highly seen in pus cells and Staphylococcus aureus was present more in blood, pus, and sputum respectively.

Emergence of Resistance: In the study, culture study reports reveal the emergence of resistance of microorganisms. E.coli was resistance to Netillin, Klebsiella pneumonia to Meropenum, staphylococcus pneumonia to Augmentin, staphylococcus aureus to Ciprofloxacin, Pseudomonas to Cefoperazone, and Streptococcus species to Nalixidic acid.

Appropriateness of antibiotics use in different departments is given in Table. 9.

Table. 9. Appropriateness of Antibiotics used in different departments

\begin{tabular}{|c|l|c|c|}
\hline S. No. & \multicolumn{1}{|c|}{ Departments } & Rational (\%) & Irrational (\%) \\
\hline 1 & General medicine (44) & 83.47 & 16.53 \\
\hline 2 & Care \& Supportive centre (27) & 77.77 & 22.23 \\
\hline 3 & Surgery $(29)$ & 82.66 & 17.34 \\
\hline
\end{tabular}

Categories of Antibiotics prescribed during the study period are detailed in Table. 10.

Table. 10. Appropriateness of Antibiotics used in different departments

\begin{tabular}{|c|c|c|c|c|}
\hline S. No. & Categories & Antibiotics & Overall $(\mathrm{n}=225)$ & Study $(n=110)$ \\
\hline 1 & Aminoglycosides & Amikacin & $54(24.0)$ & $26(23.64)$ \\
\hline 2 & \multirow{5}{*}{ Cephalosporin's } & Ceftriaxone & $29(12.9)$ & $15(13.62)$ \\
\hline 3 & & Cifipime & $20(8.9)$ & $11(10.0)$ \\
\hline 4 & & Cefixime & $05(2.22)$ & $02(1.8)$ \\
\hline 5 & & Cefatoxime & $03(1.8)$ & $01(0.91)$ \\
\hline 6 & & Cefoperazone & $02(1.2)$ & $01(0.91)$ \\
\hline 7 & \multirow[t]{3}{*}{ Fluoroquinolones } & Levofloxacin & $26(11.56)$ & $13(11.81)$ \\
\hline 8 & & Ciprofloxacin & $04(2.01)$ & $02(1.8)$ \\
\hline 9 & & Prulifloxacin & $03(1.8)$ & $01(0.91)$ \\
\hline 10 & Penicillin & Amoxcillin & $13(5.78)$ & $08(7.32)$ \\
\hline 11 & Carbapenems & Imipenum & $17(7.6)$ & $10(8.48)$ \\
\hline 12 & & Piperacillin & $21(9.34)$ & $10(9.09)$ \\
\hline
\end{tabular}


Assessment of Antibiotic Use in a Secondary Care Referral Hospital of South India

\begin{tabular}{|c|c|c|c|c|}
\hline 13 & \multirow{2}{*}{ Macrolides } & Azithromycin & $09(3.98)$ & $04(3.62)$ \\
\hline 14 & & Clarithromycin & $03(1.8)$ & $01(0.91)$ \\
\hline 15 & \multirow{4}{*}{ Anti-Tuberculosis } & Isoniazid & $04(2.01)$ & $02(1.8)$ \\
\hline 16 & & Pyrazinamide & $03(1.8)$ & $01(0.91)$ \\
\hline 17 & & Rifampicin & $03(1.8)$ & $01(0.91)$ \\
\hline 18 & & Ethambutol & $03(1.8)$ & $01(0.91)$ \\
\hline
\end{tabular}

Therapeutic indications: Indications for antibiotic use were grouped into three categories: empirical (based on clinical evidence of infection), Prophylactic (administration of antibiotics without evidence of infection) and specific use (based on culture report). Of the prescribed antibiotics, 37\% were administered empirically, 15\% for Prophylactic purpose and $48 \%$ according to the culture results. Rational use of antibiotics was significantly higher when culture reports were considered than when given empirically or used prophylactically.

National List Essential of medicines: Totally 31 drugs of antibacterials were listed in National List of Essential Medicine (India) 2011. They were only 15 antibacterials were prescribed in study population. The details of antibacterials prescribed in the study population from NLEM were shown in Table. 11.

Table. 11. List of Antibacterials as per NLEM 2011

\begin{tabular}{|c|c|c|}
\hline Medicines & Route of Administration & Strengths \\
\hline Amoxicillin & $\begin{array}{l}\text { Powder for suspension } \\
\text { Capsules }\end{array}$ & $\begin{array}{l}125 \mathrm{mg} / 5 \mathrm{ml} \\
250 \mathrm{mg} \text { or } 500 \mathrm{mg}\end{array}$ \\
\hline Cefotaxime & Injection & $125 \mathrm{mg}, 250 \mathrm{mg} \& 500 \mathrm{mg}$ \\
\hline Ceftriaxone & Injection & $250 \mathrm{mg}, 1 \mathrm{~g}$ \\
\hline Amoxicillin+Clavulinic acid & $\begin{array}{c}\text { Tablets } \\
\text { Powder for suspension } \\
\text { Injection }\end{array}$ & $\begin{array}{l}625 \mathrm{mg} \\
228.5 \mathrm{mg} / 5 \mathrm{ml} \\
600 \mathrm{mg}, 1.2 \mathrm{gm}\end{array}$ \\
\hline Cefixime & Tablet & $100,200 \mathrm{mg}$ \\
\hline Amikacin & Injection & $250 \mathrm{mg} / 2 \mathrm{ml}$ \\
\hline Azithromycin & $\begin{array}{l}\text { Tablets } \\
\text { Suspension } \\
\text { Injection }\end{array}$ & $\begin{array}{l}100,250,500 \mathrm{mg} \\
100 \mathrm{mg} / 5 \mathrm{ml} \\
500 \mathrm{mg}\end{array}$ \\
\hline $\begin{array}{l}\text { Ciprofloxacin } \\
\text { Hydrochloride }\end{array}$ & $\begin{array}{c}\text { Injection } \\
\text { Tablets }\end{array}$ & $\begin{array}{l}200 \mathrm{mg} / 100 \mathrm{ml} \\
250 \mathrm{mg}, 500 \mathrm{mg}\end{array}$ \\
\hline Ethambutol & Tablets & $200 \mathrm{mg}, 400 \mathrm{mg}, 600 \mathrm{mg}, 800 \mathrm{mg}$ \\
\hline Isoniazid & $\begin{array}{l}\text { Tablets } \\
\text { Syrup }\end{array}$ & $\begin{array}{l}50 \mathrm{mg}, 100 \mathrm{mg}, 300 \mathrm{mg} \\
100 \mathrm{mg} / 5 \mathrm{ml}\end{array}$ \\
\hline Ofloxacin & $\begin{array}{l}\text { Tablets } \\
\text { Syrup }\end{array}$ & $\begin{array}{l}100 \mathrm{mg}, 200 \mathrm{mg} \\
50 \mathrm{mg} / 5 \mathrm{ml}\end{array}$ \\
\hline Pyrazinamide & Tablets & $500 \mathrm{mg}, 750 \mathrm{mg}, 1000 \mathrm{mg}, 1500 \mathrm{mg}$ \\
\hline Rifampicin & $\begin{array}{l}\text { Capsules/Tablets } \\
\text { Syrup }\end{array}$ & $\begin{array}{l}50 \mathrm{mg}, 150 \mathrm{mg}, 300 \mathrm{mg}, 450 \mathrm{mg} \\
100 \mathrm{mg} / 5 \mathrm{ml}\end{array}$ \\
\hline
\end{tabular}

\section{Statistical Analysis}

PEARSON's Correlations coefficient(r) was calculated to find out the association between age, length of stay, total number of drugs and total number of antibiotics. At 0.01 levels significant age is positively correlated with the number of total drugs prescribed and number of antibiotics prescribed. At 0.05 levels, length of stay is positively correlated to the number of antibiotic prescribed.

ANOVA test revealed that total number of antibiotics and length of stay were found to vary significantly between the age groups $(\mathrm{p}<0.05)$ but total number of drugs were not significantly different between these age groups ( $\mathrm{p}>0.05)$.

\section{Conclusion}

In conclusion, the rational use of antibiotics will be increasingly supported by the diagnosis of bacterial infections, based on the culture sensitivity report to identify optimum treatment. Antibiotics were prescribed on clinical judgment in majority of patients rather than obtaining the culture sensitivity reports. Educational interventions emphasizing rational prescribing, along a multidirectional effort to create an update local formulary and a strict antibiotic prescribing policy can help significantly to overcome these problems and to reduce the extent of resistance to antibiotics and most effective accession in preventing the resistance of microorganisms is to ensure appropriate antibiotic use.

In order to prevent use of antibiotics for inappropriate indications and to prevent economic loss, the sale of antibiotics without prescriptions should be restricted and prescriptions should always include the period, the dosage and also the number of drugs required. 


\section{Acknowledgements}

The authors would like to thank all faculties of Raghavendra Institute of Pharmaceutical Education and Research (RIPER) and Dr. Mohanraj Rathinavelu, Assistant Professor, Department of Pharmacy Practice, RIPER and Dr. Ram Keshava Reddy (H.O.D) Department of General Medicine, Rural Development Trust Hospitals (RDT) Bathalapalli, for their valuable guidance and constant support.

\section{References}

[1] Srishyla M V,Nagarani M A, B V Venkataram. Drug utilization of antibacterials in the patient setting of the tertiary hospital .Indian Journal Pharmacology 1994;26(4):282-287.

[2] World Health Organization. WHO Global strategy for containment of antimicrobial resistance. WHO/CDS/CSR/DRS/2001.2

[3] Ian M. Gould and Jos W.M. Van Der Meer(ed). Antibiotic policies theory and practice New York: kluwer Academic/plenum publisher;2005. 